\title{
Boom and Bust: Life History, Environmental Noise, and the (un)Predictability of Jellyfish Blooms
}

\author{
Nicolas A. Schnedler-Meyer*, Thomas Kiørboe and Patrizio Mariani \\ Centre for Ocean Life, National Institute for Aquatic Resources, Technical University of Denmark, Lyngby, Denmark
}

Jellyfish (pelagic Cnidarians and Ctenophores) form erratic and seemingly unpredictable blooms with often large, transient effects on ecosystem structure. To rapidly capitalize on favorable conditions, jellyfish can employ different life histories, which are either a life cycle with one annual sexual reproduction event and an overwintering benthic stage (metagenic life cycle), or continuous reproduction and a holoplanktonic life cycle. However, the links between life history, blooms, and environmental variability are unclear. Here, we examine how environmental variability can drive the bloom dynamics of typical jellyfish in coastal enclosed or semi-enclosed temperate ecosystems. With a simple community model, we reproduce typical seasonalities of the two strategies and trophic cascades triggered by abundant jellyfish, demonstrating how erratic blooms

\section{OPEN ACCESS}

Edited by: Alberto Basset,

University of Salento, Italy

Reviewed by:

Sergio Rossi,

University of Salento, Italy José M. Riascos,

University of Valle, Colombia

*Correspondence:

Nicolas A. Schnedler-Meyer niaz@aqua.dtu.dk

Specialty section:

This article was submitted to Marine Ecosystem Ecology,

a section of the journal

Frontiers in Marine Science

Received: 25 October 2017 Accepted: 09 July 2018 Published: 31 July 2018

Citation:

Schnedler-Meyer NA, Kiørboe T and Mariani P (2018) Boom and Bust: Life History, Environmental Noise, and the (un)Predictability of Jellyfish Blooms.

Front. Mar. Sci. 5:257. doi: 10.3389/fmars.2018.00257 can be generated by irregular changes in the environment. Consistent with literature observations, we predict that metagenic jellyfish dominate early in the season, compared to holoplanktonic organisms, and are favored by increased seasonality. Our results reveal possible mechanisms driving coastal patterns of jellyfish blooms, and factors that are important for the outcome of competition between jellyfish with different life cycles. Such knowledge is important for our understanding of jellyfish blooms, which have large consequences for human activities and well-being, and may improve our ability to predict and manage local ecosystems.

Keywords: population dynamics, life cycle, reproductive strategies, environmental drivers, advection, coastal ecosystems, trait based model, seasonality

\section{INTRODUCTION}

Jellyfish outbreaks are widely recognized for their variable and unpredictable dynamics, with individuals suddenly appearing in large numbers, only to later be seemingly absent from the ecosystem (Boero et al., 2008). Such fluctuations typically have a seasonal component at temperate latitudes, but there is also important variation on interannual or longer time scales (Condon et al., 2013). Much attention has been given to these erratic jellyfish blooms, because of their often drastic consequences for local or regional ecosystem structure and functioning (Huntley and Hobson, 1978; Daskalov, 2002; Møller and Riisgård, 2007b). Most bloom-forming jellyfish are large and have zooplanktivorous diets (Hamner and Dawson, 2009), and may effectively control grazer populations when abundant (Feigenbaum and Kelly, 1984; Olesen, 1995; Schneider and Behrends, 1998; Møller and Riisgård, 2007c; Tiselius and Møller, 2017). This in turn releases primary producers from predation control, eliciting phytoplankton blooms (Møller and Riisgård, 2007b) and favoring jellyfish in the competition with fish (Riisgård et al., 2012; Robinson et al., 2014), 
in part through the effect of reduced water clarity and light on fish visual feeding efficiency (Aksnes, 2007; Haraldsson et al., 2012; Schnedler-Meyer et al., 2016). Such trophic cascades could be self-reinforcing because phytoplankton blooms often lead to oxygen depletion in enclosed shallow waters. This stimulates nutrient release from the bottom and further algal growth, and since many jellyfish are tolerant to hypoxia, they have a competitive advantage over other, more sensitive organism groups in such conditions (Decker et al., 2004; Purcell, 2012).

Though our understanding of the causality of blooms is limited, the tendency of some jellyfish to form massive blooms must be linked to a combination of their environment, its variability, and their traits (Dawson and Hamner, 2009; Hamner and Dawson, 2009). True jellyfish blooms caused by local population growth, as opposed to aggregation from other areas, often occur in coastal enclosed or semi-enclosed environments like marine lakes, lagoons, fjords, estuaries and bays (Möller, 1980; Hamner et al., 1982; Lucas and Williams, 1994; Purcell and Decker, 2005; Uye, 2005; Condon and Steinberg, 2008; Lo and Chen, 2008; Fuentes et al., 2011; Riisgård et al., 2012). In such areas, where advective loss of the slow-swimming jellyfish is restricted and production high, spectacular abundances may occur, often leading to population regulation through density dependent effects (Lucas et al., 1997; Goldstein and Riisgård, 2016). Whether blooms occur seasonally or seemingly at random, they emerge and disappear in response to changes in environmental conditions. Thus, the occurrence of blooms is linked to the magnitude and patterns of fluctuations in environmental variables such as advective displacement, temperature or salinity.

Whereas jellyfish blooms require suitable environmental conditions to occur, the ability of jellyfish to quickly respond to changes in those conditions depend on specific traits promoting high growth and reproductive rates (Pitt et al., 2013). The simple body plans of jellyfish can support rapid growth, but do not support large energy storing tissues, and the ability to cope with food shortages is therefore limited to degrowth of the entire organism. Broadly speaking, from a life history perspective, jellyfish generally employ one of two strategies to cope with environmental fluctuations, being either holoplanktonic or metagenic see (Boero et al., 2008), with ctenophores being holoplanktonic, and cnidarian jellyfish being mostly metagenic (although several holoplanktonic species exist). The two life histories are well represented by the widely distributed and well-studied Aurelia sp. (metagenic) and Mnemiopsis leidyi (holoplanktonic), which form blooms in similar environments in many temperate regions of the world. The present study is largely inspired by the dynamics of these two taxa, which are simultaneously well-studied, widely distributed, and occupy similar ecological niches.

Metagenic jellyfish maintain themselves through adverse periods in a benthic life stage that can reseed the population when favorable conditions return. The term "metagenic" is conventional in the literature, and will be used here, although benthic and pelagic generations usually coexist, and the jellyfish are therefore not truly metagenic in a strict sense of the word. This strategy is typical of scyphozoan cnidarians, which contain the majority of bloom forming species (Dawson and Hamner, 2009; Hamner and Dawson, 2009). The general scyphozoan life cycle but see (Ceh et al., 2015) involves an asexually reproducing polyp stage that releases one or more ephyrae (small jellyfish) into the water column at the onset of the productive season (Lucas et al., 2012). These ephyrae grow into adult medusae that reproduce sexually, producing small planula larvae that in turn settle as polyps, while the adults disappear at the end of the productive season (Lucas et al., 2012).

Holoplanktonic jellyfish have plastic life histories, where reproduction is opportunistic and varies with the environment, and all life stages can therefore be simultaneously present in the water column. The populations of holoplanktonic jellyfish rely on at least some individuals surviving through the bad season to quickly capitalize on renewed resources. This is typical of lobate ctenophores (e.g., Mnemiopsis leidyi), which are hermaphroditic, self-fertilizing, and able to produce offspring as juveniles, giving them short generation times (Jaspers et al., 2012; Martindale and Henry, 2015).

Both these reproductive strategies have trade-offs. For example, the polyps of metagenic jellyfish may ensure their continuity during adverse periods, may increase asexually providing a buffer against recruitment failure, and may provide the metagenic jellyfish with a head start at the beginning of the season (Boero et al., 1996, 2008; Lucas et al., 2012). However, they are also dependent on suitable polyp substrate, and the adult generation are vulnerable to high mortality rates because they cannot usually replenish in the water column. Conversely, holoplanktonic jellyfish populations depend on the number of individuals left after a period of adverse conditions, but can reproduce continuously, allowing them to recover from mortality events during the growth season (Costello et al., 2006). Thus, both strategies enable jellyfish to take advantage of transient favorable conditions, but are not equal in their advantages and disadvantages. Hence, it is interesting to investigate if and how trade-offs in the different life history strategies can interplay with environmental variability to favor one or the other.

Here, we aim to investigate the apparent erratic nature of some jellyfish blooms in enclosed or semi-enclosed waters, and to explore the relative success of the two main life history strategies of jellyfish in such areas. We focus on temperate and highly seasonal regions, where the phenologies of the two strategies contrast the most. We examine whether different types of environmental variation in advective loss can produce bloom dynamics similar to those in nature, and how the two life history strategies perform under different scenarios of advective loss and polyp habitat availability. We address these questions by introducing a relatively simple food web model containing jellyfish with the two different reproductive strategies exposed to seasonal phytoplankton dynamics and realistically fluctuating levels of water exchange (Figure 1).

\section{METHODS}

\section{Model System}

We model the seasonal cycle of dissolved inorganic nitrogen $N$, phytoplankton $P$, zooplankton $Z$, detritus $D$, metagenic 


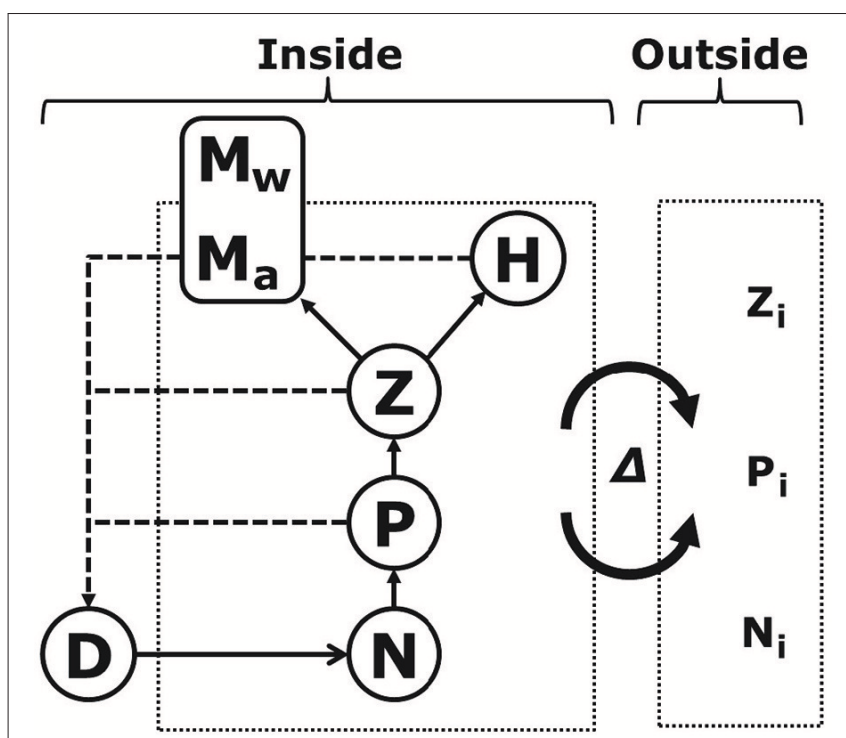

FIGURE 1 | Model system, containing a limiting nutrient $(N)$, phytoplankton $(P)$, zooplankton $(Z)$, detritus $(D)$, and two types of jellyfish, holoplantonic $(H)$ and metagenic (resolved into individual body mass $M_{w}$ and abundance $M_{a}$ ). All boxes (except $D$ and $M_{W}$ ) are mixed with water containing outside concentrations of nutrients, phytoplankton and zooplankton $\left(N_{i}, P_{i}\right.$, and $\left.Z_{i}\right)$, but no jellyfish, at a water exchange rate $\Delta$.

jellyfish $M$, and holoplanktonic jellyfish $H$ as a chemostat-type system with the common currency of nitrogen $\left(\mathrm{mmol} \mathrm{m} \mathrm{m}^{-3}\right)$. The model system interacts with surrounding water masses through a water exchange rate $\Delta$, flushing the system with water containing outside concentrations of nitrogen, phytoplankton and zooplankton $\left(N_{i}, P_{i}\right.$, and $Z_{i}$, respectively), and transporting jellyfish out of the system (Figure 1). For simplicity, we thus assume jellyfish to be absent from outside the system. Whereas all other populations are described as single state variables in units of nitrogen concentration, metagenic jellyfish biomass is resolved into individual jellyfish nitrogen content $\left(M_{w}\right)$, and abundance $\left(M_{a}\right)$, thus resolving individual and population growth.

Nitrogen dynamics are the sum of water exchange, higher trophic level excretion, remineralization of detritus and phytoplankton uptake, with phytoplankton nitrogen uptake modeled with a Michaelis-Menten formulation. The zooplankton grazes the phytoplankton following a Holling type III functional response which is typical for a coastal copepod such as Acartia spp. (Kiørboe et al., 1985), and is removed through mortality, respiration and jellyfish predation. Sinking phytoplankton and unassimilated jellyfish and zooplankton food go into the detritus, which is remineralized back into the nitrogen pool.

The model is loosely parameterized to Aurelia sp. for which such information is most readily available, and we keep the two jellyfish types in our model equal in all but life history, in order to focus on the effect of life history traits on their dynamics.

Bloom-forming jellyfish are often generalist predators that consume a wide range of zooplankton, fish fry, and eggs and even detritus in some cases. Here we focus on the typical main prey, zooplankton, and we do not consider fish in the model. While jellyfish clearance rates are typically constant for (realistic) prey concentrations (Bishop, 1967; Clifford and Cargo, 1978; Møller and Riisgård, 2007a), their growth rates do saturate, as surplus ingestion is regurgitated (Hansson and Kiørboe, 2006). Thus, whereas both types of jellyfish remove zooplankton with a linear (Holling type I) functional response, the prey is assimilated with a saturating (Holling type II) functional response, with surplus ingestion going to detritus. For both jellyfish, biomass is lost through mortality, respiration and water exchange.

A new generation of metagenic jellyfish ephyrae ( $E$, ind. $\mathrm{M}^{-3}$ ) are released once a year (March 1st), describing a typical phenology for Aurelia aurita (Lucas et al., 2012). This initial abundance decreases during the course of a season through advective loss and mortality. Any remaining biomass at the end of the season (November 1st) is moved to the detritus pool. This resets $M_{a}$ and $M_{w}$ to zero in the model, before a new cohort is added next spring.

The factors controlling maturation and reproductive allocation in adult metagenic jellyfish are not well understood, but are plastic with respect to size and seem related to food availability and age (Lucas, 2001). Additionally, Miyake et al. (1997) found that gonad maturity of Aurelia aurita accelerated with age. In our model, reproductive allocation starts at a low value in summer (July 1st), and then increases linearly to a given maximum value $(\omega)$ later in the season. We do not resolve polyp population dynamics, but rather assume independence between planula and ephyrae production. At any rate, the vast majority of planulae and polyps will perish, and consequently the production of planulae goes into to the detritus in the model.

A detailed description of all model equations can be found together with a table of parameter values (Table S1) in the Supplementary Material.

\section{Seasonality}

Seasonal dynamics in the model are forced through seasonal fluctuations in temperature and phytoplankton growth rate. Temperature affects growth, respiration, clearance, and remineralization in the model according to their respective $\mathrm{Q}_{10}$ values.

Seasonal concentrations of nitrogen, phytoplankton and zooplankton in the incoming water $\left(N_{i}, P_{i}\right.$ and $\left.Z_{i}\right)$ are calculated by running the model without jellyfish, zero water exchange $(\Delta=0)$, and a total nitrogen pool $(N+P+Z+D)$ equal to $70 \mathrm{mmol} \mathrm{N} \mathrm{m}{ }^{-3}$. The resulting seasonal concentrations of nitrogen, phytoplankton and zooplankton were then used as input concentrations for model runs including jellyfish. Under these conditions, the model reaches a steady seasonal cycle with a classical spring phytoplankton bloom followed by zooplankton increases in summer.

\section{Water Exchange Rate}

Water exchange of enclosed systems with the open ocean can be driven by many physical phenomena including density gradients that arise through differences in salinity or temperature, tidal forces or be driven by strong winds. Depending on the region, the exchanges between local and surrounding areas can occur at different intensities and at several temporal scales, 
being described by random uncorrelated fluctuations or more correlated dynamics including seasonal patterns. We simulate water exchanges as

$$
\Delta(t)=\bar{\Delta} \times \mathrm{A} \sin \left(\frac{2 \pi}{365} t-\varphi_{\Delta}\right) \times \varepsilon(t)
$$

where $\bar{\Delta}$ is the average water exchange rate, $A$ is the amplitude, $\varphi_{\Delta}$ is the time of seasonal maximum, and $\varepsilon(t)$ is some random environmental noise at time $t$. The time series generated by the formulation above can represent seasonal as well as random signals, depending on values of $\varepsilon$ and $A$. $\Delta$ is assumed to be larger in winter and lower in summer, corresponding to examples of water exchange from real systems (Austin, 2002; Riisgård et al., 2012). Note that var $\Delta$ is always a positive number.

It is expected that environmental noise is autocorrelated in time (Vasseur and Yodzis, 2004). This can be described by the spectrum of various frequencies that make up the noise signal in Equation (1). Natural noise signals often conform to a power law, where the amount of variance contributed by different frequencies scales with frequency $v$ as $1 / v^{\Upsilon}$, increasing autocorrelation as $\Upsilon$ increases (Vasseur and Yodzis, 2004). The noise is said to be "white" when the spectral exponent $\checkmark$ is close to zero and "red" for $\Upsilon \approx 1$, while "brown" noise has $\Upsilon$ values around 2 (Vasseur and Yodzis, 2004). Thus, the random noise signal at time $t$ is calculated as (Ruokolainen and McCann, 2013):

$$
\varepsilon(t)=\sum_{v=1}^{t_{\text {end }} / 2} \frac{1}{v^{\gamma / 2}} \sin \left(\frac{2 \pi v t}{t_{\text {end }}}+\theta(v)\right)
$$

where $t_{\text {end }}$ is the length of the generated time series and $\theta$ is a vector of random phases, drawn from the uniform distribution between $[0,2 \pi]$. The generated noise is then normalized to unit maximum amplitude by dividing the noise time series by its maximum absolute, before being applied to $\Delta$.

\section{Code Availability}

The MATLAB model code is available upon request to the first author.

\section{RESULTS}

\section{Seasonal Cycle}

The model is run for long multi-annual time periods, and reproduces the main features of a typical temperate seasonal cycle, with a phytoplankton bloom in the early spring followed by increased zooplankton biomass (Figure 2). In the absence of predators, zooplankton controls phytoplankton during summer, while both are low in late winter before the onset of the next season.

The numbers of metagenic jellyfish $\left(M_{a}\right)$ decline rapidly through mortality and advective loss after their introduction in early spring, but the total biomass $(M)$ increases due to growth in individual size. At low values of water exchange $(\Delta)$, medusae can maintain relatively high abundances through summer, resulting in density dependence and stunted individual growth (Table 1). Conversely, higher values of $\Delta$ result in lower biomass and abundance but larger individual size. After an early summer peak, metagenic jellyfish biomass decreases due to both loss of individuals and increased allocation into reproductive output.

Similarly, the biomass of holoplanktonic jellyfish increases in spring following increases in zooplankton biomass, but typically with a later peak than $M$, especially when winter $\Delta$ has been high (Figure 2). Moreover, whereas the initial spring biomass of metagenic jellyfish only depends on substrate availability (assumed to be constant in the model), holoplanktonic jellyfish depend on the biomass left after the winter.

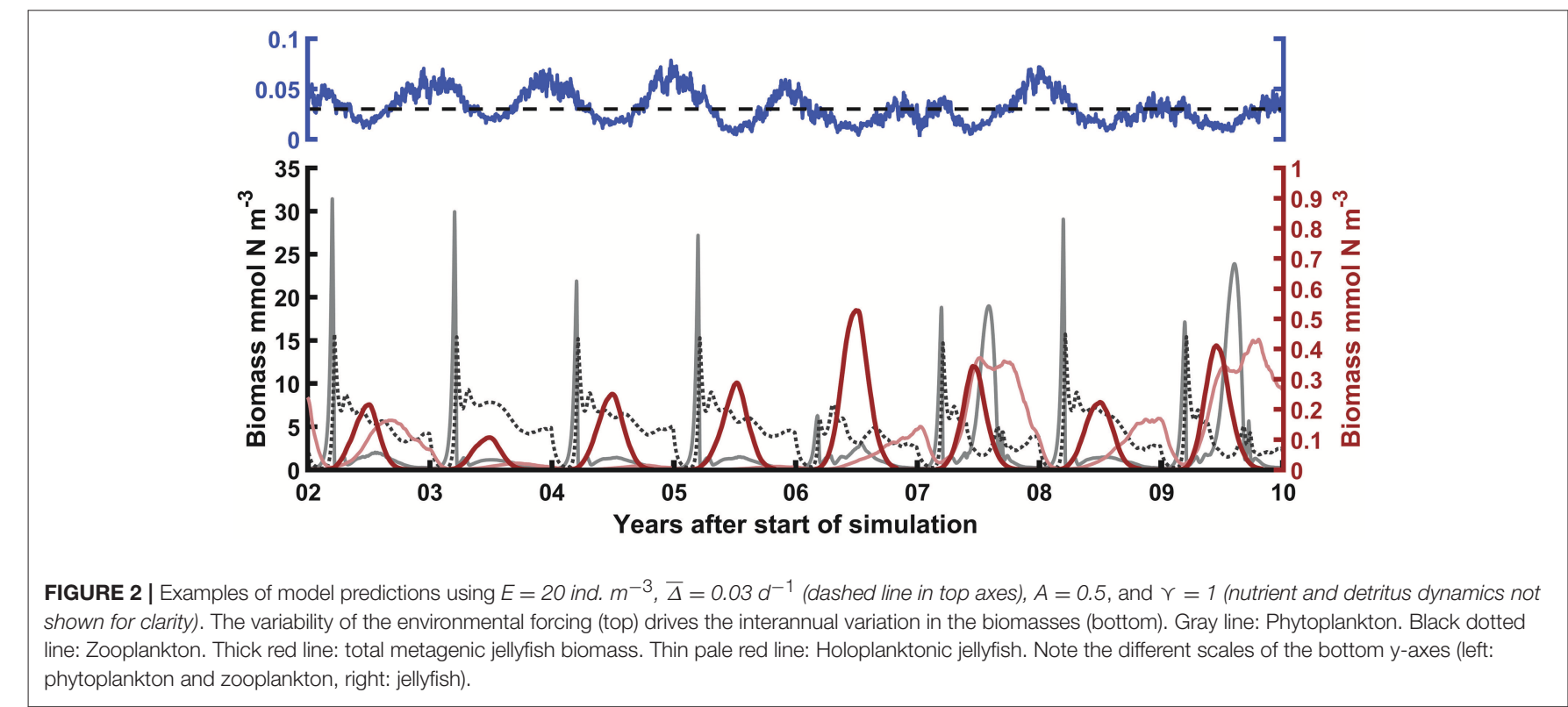




\section{Interannual Variability}

Variation in $\Delta$ introduces interannual variations in both jellyfish populations, with high biomasses of jellyfish in years of relatively low $\Delta$, and vice versa (Figure 2). In years of low $\Delta$, jellyfish are able to control zooplankton biomass, allowing the development of phytoplankton blooms during summer (Figure 2). The interannual variability in biomasses introduced by variation in $\Delta$ depends on the amplitude and temporal correlation of the forcing. The $\Delta$ variation employed in our model has two components: regular seasonal fluctuations with amplitude $A$, and random fluctuations with autocorrelation determined by the spectral exponent $\curlyvee$ (noise color). In order to show the effects of these different patterns of variation, we have run 200-year-long simulations, with different combinations of these parameters. Each run has then been aggregated into a "climatology," showing the mean and total variation of each biomass (Figure 3). Increasing $\curlyvee$ has the effect of increasing the interannual variation in $\Delta$ as the time series of the noise becomes more autocorrelated. Even though the variance, amplitude and mean of $\Delta$ is the same for different levels of $\checkmark$, the time scale of the fluctuations relative to the time scale of the population dynamics is important for the resulting variation in biomasses. Thus, the year-to-year variation in biomasses is dependent on the color of the variation in $\Delta$ (Figure 3, top to bottom). While the average biomasses (lines in Figure 3) remain relatively unchanged, the variation around the mean (shaded areas in Figure 3) increases with increasing $r$.

Conversely to changes in $\checkmark$, changes in the seasonal water exchange amplitude $(A)$ affect the average seasonal dynamics (Figure 3, left to right). As $A$ increases, the average $\Delta$ increases during the winter, and decreases during the summer. Because metagenic jellyfish only experience summer conditions, their biomass increases with $A$, while holoplanktonic jellyfish become less successful, experiencing high advective losses during the winter. The relatively low $\Delta$ during summer also results in increased frequency and magnitude of summer phytoplankton blooms.

The dependency of holoplanktonic jellyfish on the previous years' biomass causes their biomass to be interannually autocorrelated, even when there is strong interannual variation in the forcing. A linear regression of the current and previous years' maximum seasonal holoplanktonic biomass explains $75 \%$ of the variation, in simulations lasting 200 years (same conditions as in Figure 2). In comparison, the previous year only explains $32 \%$ of next year's metagenic jellyfish biomass in the same simulation.

\section{Effects of Average Water Exchange and Substrate Availability}

We also investigate the effects of the average water exchange rate $\bar{\Delta}$, and of the magnitude of spring ephyrae release $E$, which can be considered as a proxy for substrate availability and growth conditions for benthic polyps (electronic Supplementary Information, Figure S1). As already observed, total jellyfish biomass is high at low values of $\bar{\Delta}$. The magnitude of $E$, however, can control which life cycle strategy will dominate. In particular, for values of $E>25$ ind. $\mathrm{m}^{-3}$ metagenic forms will dominate the
TABLE 1 | Metagenic jellyfish abundance Ma, individual size Ms and biomass $\mathrm{M}$, at peak seasonal biomass, for different values of constant water exchange rate $\Delta$.

\begin{tabular}{lccc}
\hline $\boldsymbol{\Delta}$ & $\boldsymbol{M}_{\boldsymbol{a}}$ (ind. $\left.\mathbf{M}^{-\mathbf{3}}\right)$ & $\boldsymbol{M}_{\boldsymbol{s}}\left(\mathbf{m m o l ~ N}\right.$ ind $\left.^{-\mathbf{1}}\right)$ & $\boldsymbol{M}\left(\mathbf{m m o l ~ N ~ m}^{\mathbf{- 3}}\right)$ \\
\hline $\mathbf{0 . 0 1}$ & 7.1 & 0.10 & 0.74 \\
$\mathbf{0 . 0 2}$ & 2.46 & 0.26 & 0.64 \\
$\mathbf{0 . 0 3}$ & 0.95 & 0.38 & 0.36 \\
\hline
\end{tabular}

Simulations run with $E=20$ ind. $M-3$.

biomass, whereas we predict holoplanktonic dominance at low ephyrae release values $\left(E<20\right.$ ind. $\left.\mathrm{m}^{-3}\right)$. Increases in $\bar{\Delta}$ reduces the total biomass, and at very high values of delta $\left(>0.035 \mathrm{~d}^{-1}\right)$ total biomass of jellyfish is close to zero, hence no effects of $E$ can be expected.

\section{DISCUSSION}

The main findings of the study can be summed up as: (1) A simple model can produce seasonal patterns in biomasses of the main plankton groups that are typical of temperate environments, including trophic cascades triggered by high jellyfish biomasses. (2) Advective loss can be an important driver of jellyfish populations and variation in this driver can produce large interannual fluctuations in jellyfish biomass similar to those observed in nature. (3) Metagenic jellyfish tend to dominate earlier in the season compared to holoplanktonic jellyfish, and the metagenic strategy is favored by increases in the seasonal amplitude of the water exchange rate. (4) Biomasses of holoplanktonic jellyfish are predicted to be more interannually autocorrelated than that of metagenic jellyfish. Below we will discuss each of these predictions and compare them to observations from nature as reported in the literature. Comparison of our findings with observations are made difficult by the fact that few studies have directly investigated the effect of advective loss for jellyfish population dynamics. However, most of the available studies concern either Aurelia sp. (metagenic scyphozoans) or Mnemiopsis leidyi (a holoplanktonic lobate ctenophore), and consequently we have focused this discussion on these two taxa. These two species have contrasting strategies, occupy similar niches, and are probably the most widespread and frequently blooming jellyfish in the world.

When jellyfish biomasses are relatively low, the seasonal succession of lower trophic levels in the plankton produced by our model are typical of NPZD models (Fennel, 1995), with low biomasses in winter, followed by a spring phytoplankton bloom and subsequently high zooplankton biomass throughout summer (Figure 2). At high jellyfish biomasses however, a trophic cascade results from the suppression of zooplankton through jellyfish predation. This in turn results in relaxation of the grazing pressure on phytoplankton, and a summer phytoplankton bloom is generated (Figures 2, 3), something we do not observe in the absence of jellyfish. These dynamics are similar to observations from field studies in seasonal bay or fiord environments, where high jellyfish biomasses have also frequently been observed to reduce zooplankton abundance, causing phytoplankton blooms 


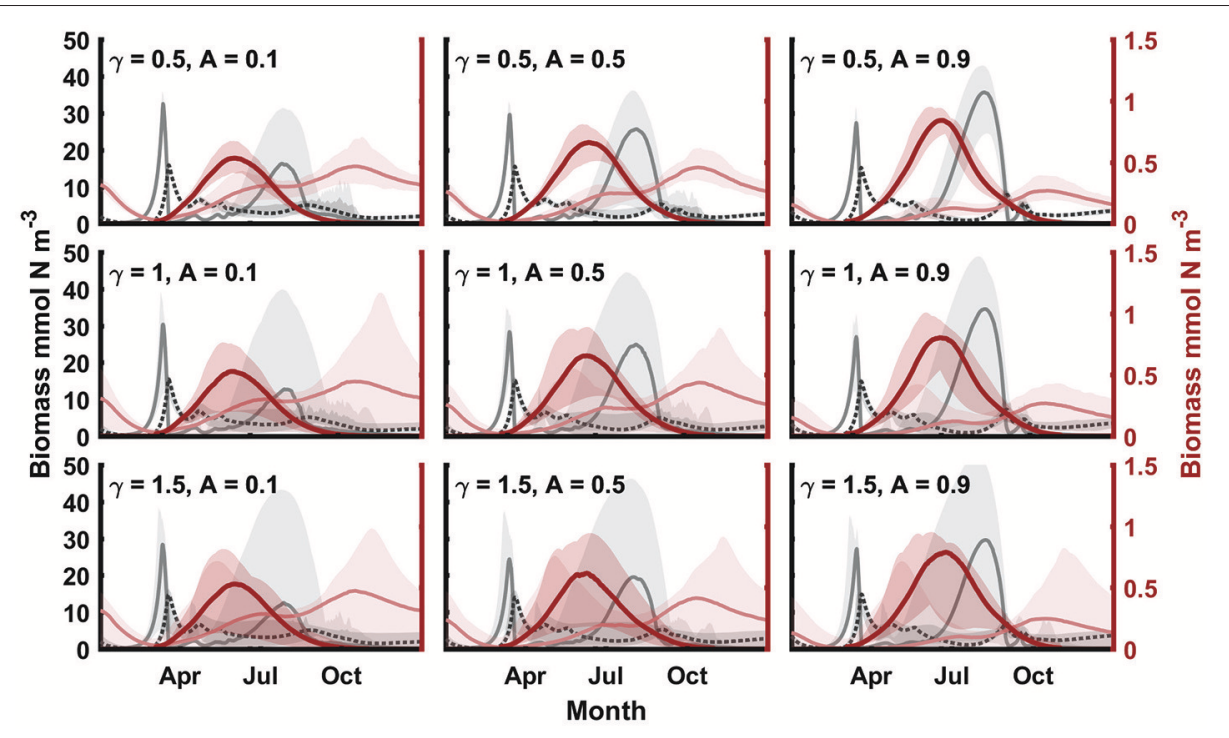

FIGURE 3 | Yearly 'climatologies' of phytoplankton (light gray dashed line), zooplankton (dark gray dotted line), medusa (thick red line) and ctenophore (light red line) mean biomass and variation (100\% quantiles, shaded areas), for different levels of environmental color (vertical) and seasonal amplitude (horizontal). For all simulations, $E=20$ ind $m^{-3}$, and $\bar{\Delta}=0.025$. Note different axis scaling for plankton (left axes in black) and jellyfish (right axes in red).

(Huntley and Hobson, 1978; Lindahl and Hernroth, 1983; Schneider and Behrends, 1998; Møller and Riisgård, 2007b; Lo and Chen, 2008; Javidpour et al., 2009; Tiselius and Møller, 2017).

We show that loss of jellyfish from a local population through advective processes $(\Delta)$ can be an important driver of jellyfish population size, structure and trait composition (Figures 2, 3, Figure S1, and Table 1). When $\Delta$ is small, jellyfish are retained in the system and may grow in size (metagenic jellyfish) or numbers (holoplanktonic jellyfish), leading to large summer jellyfish blooms. Likewise, the predicted effect of higher advective loss is to decrease overall biomass of jellyfish, but also to relax density dependent constraints on individual metagenic jellyfish. We would therefore expect jellyfish populations to be larger in enclosed systems (provided enough prey), but the individual size of metagenic jellyfish to be smaller, due to densitydependent growth limitation. The occurrence of (persistently) high jellyfish biomasses is a common phenomenon in enclosed or semi-enclosed systems, where advective losses are low (Durbin and Durbin, 1981; Ishii and Båmstedt, 1998; Costello et al., 2006). Such areas are found around the world, from tropical and subtropical marine lakes or lagoons (Hamner et al., 1982; Prieto et al., 2010), to temperate estuaries and fjords (Möller, 1980; Lucas and Williams, 1994; Purcell and Decker, 2005; Riisgård et al., 2012). In such systems, and similar to our predictions (Table 1), density dependence resulting from high jellyfish abundances is often intense, resulting in stunted growth of metagenic jellyfish (Lucas et al., 1997; Schneider and Behrends, 1998; Goldstein and Riisgård, 2016). This in turn gives rise to a generally negative relationship between metagenic jellyfish individual size and abundance (Schneider and Behrends, 1998; Lucas, 2001), at least for Aurelia sp. Reduced competition with fish due to increased turbidity and oxygen depletion have also been proposed as mechanisms behind the prevalence of jellyfish blooms in enclosed areas, where turbidity and oxygen consumption are typically high due to increased production and surface runoff (Aksnes et al., 2004; Decker et al., 2004; Shoji, 2008; Haraldsson et al., 2012; Schnedler-Meyer et al., 2016), however we propose that retention may be an alternative or additional mechanism behind the pattern, one that indeed may work either contrary to or in concert with other mechanisms (see Sørnes et al., 2007 for an interesting example).

When we vary the advective loss of jellyfish around an intermediate value, we can observe erratic interannual fluctuations in biomass that are typical of bloom forming jellyfish (Figures 2, 3). These fluctuations depend strongly on the color $(\checkmark)$ of the environmental noise, however: If the time-scale of the driver fluctuations are too short compared to the timescale of the population dynamics, they will essentially integrate over the mean driver value, even if driver variance is large (Figure 3). In nature, the color of environmental noise (e.g., in precipitation or wind patterns) tends to be "white" $(\curlyvee<0.5)$ in inland environments, and red $(\curlyvee \approx 1)$ or brown $(\curlyvee \approx 2)$ in coastal and oceanic environments, respectively (Vasseur and Yodzis, 2004). Thus, the environmental variation in the marine environments where jellyfish blooms occur may partly explain the emergence of such bloom patterns. While we have only imposed variation on the water exchange rate in this study, other environmental drivers, especially temperature, are also important for, e.g., polyp ephyrae production (Lucas et al., 2012) and will vary similarly, potentially promoting erratic blooms in the same fashion as for $\Delta$ in our model. Global, regional and local jellyfish populations do exhibit long-term oscillations (Condon et al., 2013) that correlate with climatic indices or variables (Purcell and Decker, 2005; Eriksen et al., 2012). 
The pattern of metagenic jellyfish assumed in this model is widely acknowledged as typical for scyphozoan jellyfish, however, in recent years its generality has been questioned by Ceh et al. (2015), highlighting examples of deviations from this pattern. Such deviations include examples of overwintering medusae (Miyake et al., 1997), prolonged ephyrae production (Möller, 1980), and of life cycle reversals, where e.g. medusa develop directly from planula larvae (Yasuda, 1975), especially in less seasonal and more oceanic environments. This has sparked some debate (Morandini et al., 2016; Ceh et al., 2017), with other authors arguing that exceptions are to be expected, but that they do not invalidate the general paradigm. While especially overwintering of adult medusae is more common than previously thought, we believe that the general picture of (mostly) non-overlapping cohorts of medusae that initiate before the onset of the productive season is still valid in highly seasonal environments.

Metagenic jellyfish dominate earlier in the season in our model, compared to the holoplanktonic forms. This dynamic is driven by a combination of the slower build-up of holoplanktonic jellyfish, the often lower biomass of holoplanktonic jellyfish in spring, and the onset and increase of reproduction (which does not contribute to pelagic biomass) in the metagenic jellyfish. Of these, the reproductive output of the metagenic jellyfish accounts for most of their low biomass in autumn, whereas higher holoplanktonic mortality accounts for their slower buildup in spring. Higher mortality is assigned to holoplanktonic jellyfish in the model since their individual size will on average be smaller than that of metagenic jellyfish, due to ongoing reproduction. The jellyfish phenology predicted by the model (Table 2) is corroborated by many studies comparing seasonal dynamics of metagenic (Aurelia sp.) and holoplanktonic jellyfish (mostly $M$. leidyi) in temperate regions (Kinoshita et al., 2006; Riisgård et al., 2010, 2012; Marques et al., 2015; Delpy et al., 2016); in these temperate regions, $M$. leidyi consistently blooms later in the season than Aurelia sp., though caution should be exercised, since $M$. leidyi is a warm-water adapted species.

Related to the above, the results also suggest that increased seasonality of advection will benefit the metagenic jellyfish (provided $\Delta$ peaks during winter). The most important factor for the competitive outcome in the model seems to be the relative biomasses of the two competitors at the start of the growth season. Because the metagenic jellyfish are re-seeded each spring, an important benefit of the metagenic life cycle is to buffer the effects of interannual environmental variability. Thus, we predict that holoplanktonic jellyfish are more vulnerable to yearto-year variation, at least in advective loss. Although we have not found any studies on the interannual autocorrelation of jellyfish populations, many studies of $M$. leidyi stress the importance of winter conditions and retention for local population persistence (Costello et al., 2006; Javidpour et al., 2009; Beaulieu et al., 2013; Breitburg and Burrell, 2014; David et al., 2015).

Though we have assumed populations in isolation throughout this study, in nature local populations are sometimes connected through source/sink dynamics (Riisgård et al., 2015). Jellyfish lost to advection may invade other areas, and immigration in spring from nearby habitats can negate the effect of harsh winters on holoplanktonic jellyfish (Riisgård et al., 2012). Coupling several local models similar to the one employed here with a hydrographical model could be used to shed light on such dynamics.

The metagenic jellyfish are dependent on polyps for the spawning of a new adult generation, and limitations to the settlement, survival and growth of polyps can constitute a bottleneck for the adult population (Figure S1). In a recent paper, Henschke et al. (2018) modeled Aurelia sp. population dynamics in the Gulf of Mexico using a detailed bioenergetic model of both the medusa and polyp stages, and identifying conditions for strobilation (and thus ephyrae production magnitude) and growth conditions for small medusa as the main determinants of bloom timing and magnitude. In the present study, ephyrae release was also found to be the most important determinant of metagenic biomass, as well as to affect the competitive relationship with the holoplanktonic jellyfish. In their study, Henschke et al. did not identify recruitment to the polyp stage as an important driver of Aurelia sp. dynamics, which helps justify our assumption that the influx of ephyrae in the spring and the previous years' production of planula larvae are independent. Scyphozoan polyps can reproduce asexually, may survive for more than a single season, and often produce more than one ephyrae per season (Lucas et al., 2012). In nature, most of the regulation of ephyrae production is probably acting at the polyp stage and includes predation, densitydependent competition for space, and environmental factors such as temperature (Lucas et al., 2012), and we therefore consider the assumption of independence acceptable, with the caveat that the production of ephyrae fluctuates between years. Riisgård et al. (2010) studied populations of Aurelia sp. and M. leidyi in the semi-enclosed shallow cove of Kertinge Nor, located at the bottom of a fiord. Large numbers of ephyrae (up to 300 ind. $\mathrm{M}^{-3}$ ) in spring ensured a high abundance of small, food-limited Aurelia sp., and whereas M. leidyi was present in the outer fiord where Aurelia sp. abundances were much lower, the authors concluded that high ephyrae production excluded $M$. leidyi from establishing in the inner part. Similar situations have been observed in Mediterranean French lagoons (Marques et al., 2015; Delpy et al., 2016), with similar conclusions.

Globally, release of jellyfish (both holoplanktonic and metagenic) from competition with fish probably play an important role in the increasing trends of some jellyfish populations (Mills, 1995; Llope et al., 2011; Robinson et al., 2014; Schnedler-Meyer et al., 2016), with eutrophication and climate change (especially temperature increases) being other important drivers of changes in baseline jellyfish abundance (Brodeur et al., 1999; Purcell et al., 2007). We have treated global trends related to these large-scale drivers elsewhere (SchnedlerMeyer et al., 2016), and have in the present paper focused on the effects of life history and advection on localized and short-term dynamics of jellyfish populations (including blooms), in a specific environment often characterized by high jellyfish abundances. In order to better examine the interaction between life cycle and environment, we have therefore kept the two jellyfish in our model as equal as possible, and have, for 
the sake of simplicity, ignored other important competitors (e.g., fish) and intraguild predation among jellyfish, as well as ontogenetic changes in the zooplankton diets of jellyfish that may influence seasonal dynamics and competitive patterns (Tiselius and Møller, 2017). To isolate the effect of advection, we have assumed fixed phenologies of phytoplankton growth and ephyrae production, even though they vary in nature (Lucas et al., 2012). Caveats aside, our study offer insight into mechanisms regulating jellyfish blooms in coastal and semi-enclosed areas, emphasizing particularly how advection and retention should be considered as potentially important for jellyfish population dynamics, and how ephemeral jellyfish blooms can result from environmental noise in combination with jellyfish life history. In addition, we have considered the relative merits of the two contrasting life cycle strategies of jellyfish in a quantitative way, identifying conditions for polyps, as well as seasonal amplitude and year-to-year variation in advective loss as factors that may shift the relative success of these two strategies.

Jellyfish are not the only planktonic organism group to contain species with either a holoplanktonic or metagenic life cycle. Indeed, metagenic species are common in many plankton groups such as diatoms, dinoflagellates, rotifers and copepods, to name a few (Marcus and Boero, 1998). The presence of both strategies in many different and diverse groups suggest that these two strategies must have clear and universal trade-offs that are more related to the environment than evolutionary constraints. Our results show how the interaction between life history, seasonality and more irregular environmental fluctuations may govern bloom dynamics and composition of local plankton communities driven by advection, such as in coastal areas or at upwelling sites,

\section{REFERENCES}

Aksnes, D. L., Nejstgaard, J., Sædberg, E., and Sørnes, T. (2004). Optical control of fish and zooplankton populations. Limnol. Oceanogr. 49, 233-238. doi: $10.4319 /$ lo.2004.49.1.0233

Aksnes, D. L. (2007). Evidence for visual constraints in large marine fish stocks. Limnol. Oceanogr. 52, 198-203. doi: 10.4319/lo.2007.52.1.0198

Austin, J. A. (2002). Estimating the mean ocean-bay exchange rate of the Chesapeake Bay. J. Geophys. Res. 107, 1-8. doi: 10.1029/2001JC001246

Beaulieu, W. T., Costello, J. H., Klein-Macphee, G., and Sullivan, B. K. (2013). Seasonality of the ctenophore Mnemiopsis leidyi in Narragansett Bay, Rhode Island. J. Plankton Res. 35, 785-791. doi: 10.1093/plankt/fbt041

Bishop, J. W. (1967). Feeding rates of the ctenophore, mnemiopsis leidyi. Chesapeake Sci. 6, 259-264. doi: 10.2307/1350344

Boero, F., Belmonte, G., Fanelli, G., Piraino, S.,and Rubino, F. (1996). The continuity of living matter and the discontinuities of its constituents: do plankton and benthos really exist? Trends Ecol. Evol. (Amst). 11, 177-180. doi: 10.1016/0169-5347(96)20007-2

Boero, F., Bouillon, J., Gravili, C., Miglietta, M. P., Parsons, T., and Piraino, S. (2008). Gelatinous plankton: irregularities rule the world (sometimes). Mar. Ecol. Prog. Ser. 356, 299-310. doi: 10.3354/meps07368

Breitburg, D. L., and Burrell, R. (2014). Predator-mediated landscape structure: Seasonal patterns of spatial expansion and prey control by Chrysaora quinquecirrha and Mnemiopsis leidyi. Mar. Ecol. Prog. Ser. 510, 183-200. doi: 10.3354/meps 10850

Brodeur, R. D., Mills, C. E., Overland, J. E., Walters, G. E.,and Schumacher, J. D. (1999). Evidence for a substantial increase in gelatinous zooplankton in the and possibly also of communities driven by other environmental variables such as temperature, light or nutrient supply.

We emphasize how theoretical models like the one developed here can provide insight and clarify hypotheses for specific ecological questions, and hopefully inspire other studies to test the predictions and conclusions made here.

\section{AUTHOR CONTRIBUTIONS}

All authors contributed in conceiving the study. NS-M performed modeling work, with the help of PM, NS-M collected literature references. NS-M, PM, and TK analyzed model output. NS-M wrote the first draft of the manuscript, and all authors contributed substantially to revisions.

\section{FUNDING}

The Centre for Ocean Life is supported by the Villum Foundation.

\section{ACKNOWLEDGMENTS}

The authors would like to thank Lene Friis Møller and Nando Boero for inspiration and constructive feedback in the conception of this study.

\section{SUPPLEMENTARY MATERIAL}

The Supplementary Material for this article can be found online at: https://www.frontiersin.org/articles/10.3389/fmars. 2018.00257/full\#supplementary-material
Bering Sea, with possible links to climate change. Fish. Oceanogr. 8, 296-306. doi: 10.1046/j.1365-2419.1999.00115.x

Ceh, J., Gonzalez, J., Pacheco, A. S., and Riascos, J. M. (2015). The elusive life cycle of scyphozoan jellyfish - Metagenesis revisited. Sci. Rep. 5, 1-13. doi: 10.1038/srep12037

Ceh, J., Pacheco, A. S., and Riascos, J. M. (2017). Solving an old puzzle by dismissing new pieces? Moving beyond scientific traditions to understand the life cycle of scyphozoan jellyfish: Reply to Morandini et al. (2016). Bull. Mar. Sci. 93, 857-862. doi: 10.5343/bms.2016.1088

Clifford, H. C., and Cargo, D. G. (1978). Feeding Rates of the Sea Nettle, Chrysaora quinquecirrha, under laboratory conditions. Estuaries 1, 58-61. doi: $10.2307 / 1351651$

Condon, R. H., Duarte, C. M., Pitt, K. A., Robinson, K. L., Lucas, C. H., Sutherland, K. R., et al. (2013). Recurrent jellyfish blooms are a consequence of global oscillations. Proc. Nat. Acad. Sci. U.S.A. 110, 1000-1005. doi: 10.1073/pnas.1210920110

Condon, R. H., and Steinberg, D. K. (2008). Development, biological regulation, and fate of ctenophore blooms in the York River estuary, Chesapeake Bay. Mar. Ecol. Pro. Ser. 369, 153-168. doi: 10.3354/meps07595

Costello, J. H., . Sullivan, B. K., Gifford, D. J., Van-Keuren, D., and Sullivan, L. J. (2006). Seasonal refugia, shoreward thermal amplification, and metapopulation dynamics of the ctenophore Mnemiopsis leidyi in Narragansett Bay, Rhode Island. Limnol. Oceanogr. 51, 1819-1831.doi: 10.4319/lo.2006.51.4.1819

Daskalov, G. M. (2002). Overfishing drives a trophic cascade in the Black Sea. Mar. Ecol. Pro. Ser. 225, 53-63. doi: 10.3354/meps225053

David, C., Vaz, S., Loots, C., Antajan, E., van der Molen, J., and TraversTrolet, M. (2015). Understanding winter distribution and transport pathways 
of the invasive ctenophore Mnemiopsis leidyi in the North Sea: coupling habitat and dispersal modelling approaches. Biol. Invasions 17, 2605-2619. doi: 10.1007/s10530-015-0899-y

Dawson, M. N., and Hamner, W. M. (2009). A character-based analysis of the evolution of jellyfish blooms: adaptation and exaptation. Hydrobiologia 616, 193-215. doi: 10.1007/s10750-008-9591-x

Decker, M. B., Breitburg, D. L., and Purcell, J. E. (2004). Effects of low dissolved oxygen on zooplankton predation by the ctenophore Mnemiopsis leidyi. Mar. Ecol. Pro. Ser. 280, 163-172. doi: 10.3354/meps280163

Delpy, F., Albouy-Boyer, S., Pagano, M., Thibault, D., Blanchot J., Guilhaumon, F., et al. (2016). Identifying the drivers of abundance and size of the invasive ctenophore Mnemiopsis leidyi in Northwestern Mediterranean lagoons. Mar. Environ. Res. 119, 114-125. doi: 10.1016/j.marenvres.2016.05.026

Durbin, A. G., and Durbin, E. G. (1981). Standing Stock and Estimated Production Rates of Phytoplankton and Zooplankton in Narragansett Bay, Rhode Island. Estuaries 4, 24-41. doi: 10.2307/1351540

Eriksen, E., Prozorkevich, D., Trofimov, A., and Howell, D., et al. (2012). Biomass of scyphozoan jellyfish, and its spatial association with 0-group fish in the barents sea. PLoS ONE 7:e33050. doi: 10.1371/journal.pone.0033050

Feigenbaum, D., and Kelly, M. (1984). Changes in the lower Chesapeake Bay food chain in presence of the sea nettle Chrysaora quinquecirrha (Scyphomedusa). Mar. Ecol. Prog. Ser., 19, 39-47. doi: 10.3354/meps019039

Fennel, W. (1995). A model of the yearly cycle of nutrients and plankton in the Baltic Sea. J. Mar. Sys. 6, 313-329. doi: 10.1016/0924-7963(94)00031-6

Fuentes, V., Straehler-Pohl, I., Atienza, D., Franco, I., Tilves, U., Gentile, M., et al. (2011). Life cycle of the jellyfish Rhizostoma pulmo (Scyphozoa: Rhizostomeae) and its distribution, seasonality and inter-annual variability along the Catalan coast and the Mar Menor (Spain, NW Mediterranean). Mar. Biol. 158, 2247-2266. doi: 10.1007/s00227-011-1730-7

Goldstein, J., and Riisgård, H. U. (2016). Population dynamics and factors controlling somatic degrowth of the common jellyfish, Aurelia aurita, in a temperate semi-enclosed cove (Kertinge Nor, Denmark). Mar. Biol. 163, 1-12. doi: 10.1007/s00227-015-2802-x

Hamner, W. M., and Dawson, M. N. (2009). A review and synthesis on the systematics and evolution of jellyfish blooms: advantageous aggregations and adaptive assemblages. Hydrobiologia 616, 161-191. doi: 10.1007/s10750-008-9620-9

Hamner, W. M., Gilmer, R. W., and Hamner, P. P. (1982). The physical, chemical, and biological characteristics of a stratified, saline, sulfide lake in Palau. Limnol. Oceanogr. 27, 896-909. doi: 10.4319/lo.1982.27.5.0896

Hansson, L. J., and Kiørboe, T. (2006). Effects of large gut volume in gelatinous zooplankton: ingestion rate, bolus production and food patch utilization by the jellyfish Sarsia tubulosa. J. Plankton Res. 28, 937-942. doi: 10.1093/plankt/fbl030

Haraldsson, M., Tönnesson, K., Tiselius, P., Thingstad,T. F., and Aksnes, D. L. (2012). Analysis of the relationship between fish and jellyfish as a function of eutrophication and water clarity. Mar. Ecol. Prog. Ser. 471, 73-85. doi: 10.3354/meps10036

Henschke, N., Stock, C. A., and Sarmiento, J. L. (2018). Modeling population dynamics of scyphozoan jellyfish (Aurelia spp.) in the Gulf of Mexico. Mar. Ecol. Prog. Ser. 591, 167-183. doi: 10.3354/meps12255

Huntley, M. E., and Hobson, L. A. (1978). Medusa predation and plankton dynamics in a temperate fjord, British Columbia. J.Fish.Res.Board Can. 35, 257-261. doi: 10.1139/f78-042

Ishii, H., and Båmstedt, U. (1998). Food regulation of growth and maturation in a natural population of Aurelia aurita (L.). J. Plankton Res. 20, 805-816. doi: $10.1093 /$ plankt/20.5.805

Jaspers, C., Haraldsson, M., Bolte, S., Reusch, T. B., Thygesen, U, H., and Kiørboe T. (2012). Ctenophore population recruits entirely through larval reproduction in the central Baltic Sea. Biol. Lett. 8, 809-812. doi: 10.1098/rsbl.2012.0163

Javidpour, J., Molinero, J. C., Peschutter, J.,and Sommer, U. (2009). Seasonal changes and population dynamics of the ctenophore Mnemiopsis leidyi after its first year of invasion in the Kiel Fjord, Western Baltic Sea. Biol. Invasions 11, 873-882. doi: 10.1007/s10530-008-9300-8

Kinoshita, J., Hiromi, J., and Yamada, Y. (2006). Abundance and biomass of scyphomedusae, Aurelia aurita and Chrysaora melanaster, and Ctenophora, Bolinopsis mikado, with estimates of their feeding impact on zooplankton in Tokyo Bay, Japan. J. Oceanogr. 62, 607-615. doi: 10.1007/s10872-006-0080-4
Kiørboe, T., Møhlenberg, F., and Hamburger, K. (1985). Bioenergetics of the planktonic copepod Acartia tonsa: relation between feeding, egg production and respiration, and compostion of specific dynamics action. Mar. Ecol. Prog. Ser. 26, 85-97. doi: 10.3354/meps026085

Lindahl, O., and Hernroth, L. (1983). Phyto-Zooplankton Community in Coastal Waters of Western Sweden - An Ecosystem Off Balance? Mar. Ecol. Prog. Ser. 10, 119-126. doi: 10.3354/meps010119

Llope, M., Daskalov, G. M., Rouyer, T. A., Mihneva, T. A., Chan, K.-S., Grishin, A. N. et al. (2011). Overfishing of top predators eroded the resilience of the Black Sea system regardless of the climate and anthropogenic conditions. Glob. Chang. Biol.17, 1251-1265. doi: 10.1111/j.1365-2486.2010.02331.x

Lo, W. T., and Chen, I. L. (2008). Population succession and feeding of scyphomedusae, Aurelia aurita, in a eutrophic tropical lagoon in Taiwan. Estuar. Coast. Shelf Sci. 76, 227-238. doi: 10.1016/j.ecss.2007.07.015

Lucas, C. H. (2001). Reproduction and life history strategies of the common jellyfish, Aurelia aurita, in relation to its ambient environment. Hydrobiologia 451, 229-246. doi: 10.1023/A:1011836326717

Lucas, C. H., Graham, W. M., and Widmer, C. (2012). Jellyfish life histories: role of polyps in forming and maintaining scyphomedusa populations. Adv. Mar. Biol. 63, 133-196. doi: 10.1016/B978-0-12-394282-1.00003-X

Lucas, C. H., Hirst, A. G., and Williams, J. A. (1997). Plankton Dynamics and Aurelia aurita Production in Two Contrasting Ecosystems: comparisons and consequences. Estuar. Coast. Shelf Sci. 45, 209-219. doi: 10.1006/ecss.1996.0173

Lucas, C. H., and Williams, J. A. (1994). Population dynamics of the scyphomedusa Aurelia aurita in Southampton Water. J. Plankton Res. 16, 879-895. doi: $10.1093 /$ plankt/16.7.879

Marcus, N. H., and Boero, F. (1998). Minireview: the importance of benthic-pelagic coupling and the forgotten role of life cycles in coastal aquatic systems. Limnol. Oceanogr. 43, 763-768. doi: 10.4319/lo.1998.43.5.0763

Marques, R., Albouy-Boyer, S., Delpy, F., Carré, C., Le Floc'h,E., Roques, R., et al. (2015). Pelagic population dynamics of Aurelia sp. in French Mediterranean lagoons. J. Plankt.Res. 37, 1019-1035. doi: 10.1093/plankt/fbv059

Martindale, M. Q., and Henry, J. Q. (2015). "Ctenophora," in Evolutionary Developmental Biology of Invertebrates 1: Introduction, Non-Bilateria, Acoelomorpha, Xenoturbellida, Chaetognatha, ed A. Wanninger (Wien: Springer-Verlag Wien), 179-201.

Mills, C. E. (1995). Medusae, siphonophores, and ctenophores as planktivorous predators in changing global ecosystems. ICES J. Mar. Sci. 52, 575-581. doi: 10.1016/1054-3139(95)80072-7

Miyake, H., Iwao, K., and Kakinuma, Y. (1997). Life History and Environment of Aurelia aurita. South Pac. Study, 17, 273-285.

Möller, H. (1980). Population dynamics of Aurelia aurita medusae in Kiel Bight, Germany (FRG). Mar. Biol. 60, 123-128. doi: 10.1007/BF00389155

Møller, L. F., and Riisgård, H. U. (2007a). Feeding, bioenergetics and growth in the common jellyfish Aurelia aurita and two hydromedusae, Sarsia tubulosa and Aequorea vitrina. Mar. Ecol. Prog. Ser. 346, 167-177. doi: 10.3354/mep s06959

Møller, L. F., and Riisgård, H. U. (2007b). Impact of jellyfish and mussels on algal blooms caused by seasonal oxygen depletion and nutrient release from the sediment in a Danish fjord. J. Exp. Mar. Biol. Ecol. 351, 92-105. doi: 10.1016/j.jembe.2007.06.026

Møller, L. F., and Riisgård, H. U. (2007c). Population dynamics, growth and predation impact of the common jellyfish Aurelia aurita and two hydromedusae, Sarsia tubulosa, and Aequorea vitrina in Limfjorden (Denmark). Mar. Ecol. Prog. Ser. 346, 153-165. doi: 10.3354/meps06960

Morandini, A. C., Schiariti, A., Stampar, S. N., Maronna, M. M., StraehlerPohl, I.,and Marques, A C. (2016). Succession of generations is still the general paradigm for scyphozoan life cycles. Bull. Mar. Sci. 92, 343-351. doi: $10.5343 /$ bms.2016.1018

Olesen, N. (1995). Clearance potential of jellyfish Aurelia aurita, and predation impact on zooplankton in a shallow cove. Mar. Ecol. Prog. Ser. 124, 63-72. doi: 10.3354/meps124063

Pitt K. A., Duarte C. M., Lucas C. H., Sutherland K. R., Condon R. H., Mianzan H. et al. (2013). Jellyfish body plans provide allometric advantages beyond low carbon content. PLoS ONE, 8:10. doi: 10.1371/journal.pone.0072683

Prieto, L., Astorga, D., Navarro, G.,and Ruiz, J. (2010). Environmental control of phase transition and polyp survival of a massive-outbreaker jellyfish. PLoS ONE 5:e13793. doi: 10.1371/journal.pone.0013793 
Purcell, J. E. (2012). Jellyfish and ctenophore blooms coincide with human proliferations and environmental perturbations. Ann. Rev. Mar. Sci. 4, 209-235. doi: 10.1146/annurev-marine-120709-142751

Purcell, J. E., and Decker, M. B. (2005). Effects of climate on relative predation by scyphomedusae and ctenophores on copepods in Chesapeake Bay during 1987-2000. Limnol. Oceanogr. 50, 376-387. doi: 10.4319/lo.2005.50. 1.0376

Purcell, J. E., Uye, S., and Lo, W. T. (2007). Anthropogenic causes of jellyfish blooms and their direct consequences for humans: a review. Mar. Ecol. Prog. Ser. 350, 153-174. doi: 10.3354/meps07093

Riisgård, H. U., Goldstein, J., Lundgreen, K., and Lüskow, F. (2015). Jellyfish and Ctenophores in the Environmentally Degraded Limfjorden (Denmark) During 2014 - Species Composition, Population Densities and Predation Impact. Fish. Aquac. J. 6:137. doi: 10.4172/2150-3508.1000137

Riisgård, H. U., Andersen, P., and Hoffmann, E. (2012). From fish to jellyfish in the eutrophicated Limfjorden (Denmark). Estuar. Coasts 35, 701-713. doi: 10.1007/s12237-012-9480-4

Riisgård, H. U., Barth-Jensen, C., and Madsen, C. V. (2010). High abundance of the jellyfish Aurelia aurita excludes the invasive ctenophore Mnemiopsis leidyi to establish in a shallow cove (Kertinge Nor, Denmark). Aquat. Invasions 5, 347-356. doi: 10.3391/ai.2010.5.4.03

Riisgård, H. U., Jaspers, C., Serre, S.,and Lundgreen, K. (2012). Occurrence, inter-annual variability and zooplankton-predation impact of the invasive ctenophore Mnemiopsis leidyi and the native jellyfish Aurelia aurita in Limfjorden (Denmark) in 2010 and 2011. Bioinvasions Rec. 1, 145-159. doi: 10.3391/bir.2012.1.3.01

Robinson, K. L., Graham, W. M., Brodeur, R. D., Ruzicka, J. J., Decker M. B., Hernandez, F. J., et al. (2014). Jellyfish, Forage Fish, and the World's Major Fisheries. Oceanography 27, 104-115. doi: 10.5670/oceanog. 2014.90

Ruokolainen, L., and McCann, K. (2013). Environmental weakening of trophic interactions drives stability in stochastic food webs. J. Theor. Biol. 339, 36-46. doi: 10.1016/j.jtbi.2013.08.021

Schnedler-Meyer, N. A., Mariani, P., and Kiørboe, T. (2016). The global susceptibility of coastal forage fish to competition by large jellyfish. Proc. R. Soc. B Biol. Sci.283, 1-8. doi: 10.1098/rspb.2016.1931
Schneider, G., and Behrends, G. (1998). Top-down control in a neritic plankton system by Aurelia aurita medusae - A summary. Ophelia 48, 71-82. doi: 10.1080/00785236.1998.10428677

Shoji, J. (2008). Non-size-selective predation on fish larvae by moon jellyfish Aurelia aurita under low oxygen concentrations. Plankt. Benthos Res. 3, 114-117. doi: 10.3800/pbr.3.114

Sørnes, T. A., Aksnes, D. L., Båmstedt, U., and Youngbluth, M. J. (2007). Causes for mass occurrences of the jellyfish Periphylla periphylla: a hypothesis that involves optically conditioned retention. J. Plankton Res. 29, 157-167. doi: 10.1093/plankt/fbm003

Tiselius, P., and Møller, L. F. (2017). Community cascades in a marine pelagic food web controlled by the non-visual apex predator Mnemiopsis leidyi. J. Plankton Res. 39, 271-279. doi: 10.1093/plankt/fbw096

Uye, S. (2005). Population biomass, feeding, respiration and growth rates, and carbon budget of the scyphomedusa Aurelia aurita in the Inland Sea of Japan. J. Plankton Res. 27, 237-248. doi: 10.1093/plankt/fbh172

Vasseur, D. A., and Yodzis, P. (2004). The color of environmental noise. Ecology 85, 1146-1152. doi: 10.1890/02-3122

Yasuda, T. (1975). Ecological studies on the jelly-fish, Aurelia aurita (Linné), in Urazoko bay, Fukui prefecture-XI. An observation on ephyra formation. Publ. Seto Mar. Biol. Lab. 22, 75-80. doi: 10.5134/175889

Conflict of Interest Statement: The authors declare that the research was conducted in the absence of any commercial or financial relationships that could be construed as a potential conflict of interest.

The reviewer SR and handling editor declared their shared affiliation at time of review.

Copyright (c) 2018 Schnedler-Meyer, Kiørboe and Mariani. This is an open-access article distributed under the terms of the Creative Commons Attribution License (CC $B Y)$. The use, distribution or reproduction in other forums is permitted, provided the original author(s) and the copyright owner(s) are credited and that the original publication in this journal is cited, in accordance with accepted academic practice. No use, distribution or reproduction is permitted which does not comply with these terms. 